\title{
Associations between the portion sizes of food groups consumed and measures of adiposity in the British National Diet and Nutrition Survey
}

\author{
Mary T. Kelly ${ }^{1}$, Kirsten L. Rennie ${ }^{1,2}$, Julie M. W. Wallace ${ }^{1}$, Paula J. Robson ${ }^{3}$, Robert W. Welch ${ }^{1}$, \\ Mary P. Hannon-Fletcher ${ }^{1}$ and M. Barbara E. Livingstone ${ }^{1 *}$ \\ ${ }^{1}$ Northern Ireland Centre for Food and Health (NICHE), University of Ulster, Cromore Road, Coleraine BT52 1SA, UK \\ ${ }^{2}$ Unilever Corporate Research, Colworth House, Sharnbrook, Bedfordshire MK44 1LQ, UK \\ ${ }^{3}$ School of Public Health, University of Alberta, Edmonton, AB, Canada T6G $2 G 3$
}

(Received 6 February 2008 - Revised 5 August 2008 - Accepted 5 August 2008 - First published online 10 October 2008)

The objective of the present study was to examine the associations between the portion sizes of food groups consumed with measures of adiposity using data from the National Diet and Nutrition Survey of British adults. Seven-day weighed dietary records, physical activity diaries and anthropometric measurements were used. Foods eaten were assigned to thirty different food groups and analyses were undertaken separately for men and women. The median daily portion size of each food group consumed was calculated. The potential misreporting of dietary energy intake (EI) was identified using the following equation: EI - estimated energy requirements $\times 100=$ percentage of under-reporting (UR) of energy needs. Multinomial logistic regression (adjusted for age, social class, physical activity level and UR) was used to determine the portion sizes of food groups most strongly associated with obesity status. Few positive associations between the portion sizes of food groups consumed and obesity status were found. However, UR was prevalent, with a median UR of predicted energy needs of 34 and $33 \%$ in men and women, respectively. After the adjustment was made for UR, more associations between the food groups and obesity status became apparent in both sexes. The present study suggests that the true effect of increased portion size of foods on obesity status may be masked by high levels of UR. Alternatively, these data may indicate that an increased risk of obesity is not associated with specific foods/food groups but rather with an overall increase in the range of foods and food groups being consumed.

Obesity: Portion size: Under-reporting

The prevalence of obesity is rapidly increasing in the UK, with about two-thirds of the adult population now either overweight or obese ${ }^{(1)}$. Overweight and obesity are associated with a host of adverse health outcomes such as diabetes, CVD and certain cancers $^{(2)}$. Although the specific underlying causes of weight gain in adults remain unclear, a number of environmental factors have been identified as drivers of an excess energy intake (EI) in the face of reduced energy needs.

One particular alteration in dietary patterns which has been associated with promoting obesity is the trend towards larger food portions. Consumers may be increasingly underestimating their portion sizes and EI as they eat out of the home more often or eat larger portions within the home ${ }^{(3,4)}$. It has also been suggested that consumers cannot precisely judge the amount of food they consume over the course of a few days or weeks $^{(5)}$. The passive over-consumption associated with large food portions could potentially lead to increased EI at the time of eating and over subsequent days, and, if not compensated for, could be a significant factor contributing towards excess weight gain and obesity. Thus, the reliance on self-monitoring to control food and EI to maintain a healthy body weight has becoming increasingly difficult in our obesogenic environment.
Larger food portions have been shown to increase EI in adults at single eating occasions ${ }^{(6-11)}$ and over the course of $2^{(12)}$ and $11 \mathrm{~d}^{(13)}$, under semi-controlled laboratory conditions. To date, only one study ${ }^{(14)}$ has examined the extent to which large food portions affect EI in free-living populations.

The aim of the present study was to examine the association between the portion sizes of foods consumed with indices of obesity status (BMI and waist action level (WAL)) in freeliving adults aged 19-64 years in the British National Diet and Nutrition Survey (NDNS).
Methods
Survey design
The NDNS is a programme of cross-sectional surveys of different age groups designed to be representative of Great Britain. This analysis is based on the survey undertaken between July 2001 and June 2002 in adults aged 19-64 years. The survey methodology has been described in detail elsewhere $^{(15)}$. Data from the NDNS adult survey were obtained from the UK Data Archive, University of Essex.

Abbreviations: EER, estimated energy requirements; EI, energy intake; NDNS, National Diet and Nutrition Survey; UR, under-reporting; WAL, waist action level. * Corresponding author: Professor M. Barbara E. Livingstone, fax +44 28 70323023, email mbe.livingstone@ulster.ac.uk 


\section{Dietary measures}

Subjects completed a 7-d weighed dietary record of all foods and drinks consumed both within and outside of the home. Each subject was issued a set of digital food scales and two recording diaries: the 'home record' and a smaller 'eating and drinking away from home' diary. The subjects were also issued with a pocket-sized notebook for recording any of this information in circumstances where they were reluctant, or it was inappropriate, to carry the 'eating out' diary. They were shown how to weigh and record leftovers and how to record any food that was spilt or otherwise lost. The 'eating out' diary was intended for use only when it was not possible to weigh the food items. In these cases, the subjects were asked to record as much information as they could about each food item consumed, in particular the portion size consumed and an estimate of leftovers, in addition to descriptions, brand names, price and the time and the place where food was purchased. Intakes of nutrients were calculated from the records of food consumption using the Food Standards Agency nutrient databank $^{(15)}$. All foods from the NDNS dataset were assigned to thirty different food groups. Twenty-eight of these food groups were calculated by the Office for National Statistics ${ }^{(15)}$. An additional two food groups - confectionery and soft drinks - were also calculated, because of their potential association with overweight and obesity ${ }^{(16,17)}$. Only subjects who consumed the foods from a particular food group were included in the analyses of that food group. The total quantity $(\mathrm{g} / \mathrm{d})$ of each food group consumed on a daily basis and median daily portion size of each food group consumed were calculated.

\section{Under-reporting}

Using data from the physical activity diaries that were kept concurrently with the dietary record, physical activity levels were calculated to assign the appropriate estimated energy requirements (EER) equation to the individual's activity needs ${ }^{(18)}$. Physical activity levels were calculated from the time spent in sleep, light, moderate and vigorous intensity activities for each day of recording for each subject. The time spent in each type of activity was multiplied by a metabolic equivalent to give a total metabolic equivalent hours of activity per day. These were summed up to give a mean metabolic equivalent score for the week and were then divided by $24 \mathrm{~h}$ to give a physical activity level. The published equations of the 2002 Institute of Medicine of the National Academies were used to calculate EER on an individual basis ${ }^{(19)}$. These equations, which are derived from doubly labelled water energy expenditure data, are sex and age specific, and are based on the age, weight and height of the subject. They categorise four levels of activity: sedentary; low activity; active; very active. Potential misreporting of dietary EI was identified using the following equation:

$$
\mathrm{EI}-\mathrm{EER} / \mathrm{EER} \times 100=\text { percentage of UR of energy needs. }
$$

\section{Anthropometric measurements}

Anthropometric measurements recorded have been described previously ${ }^{(20)}$. Height was measured in duplicate to the nearest $0.1 \mathrm{~cm}$ in bare feet using a portable stadiometer (Leicester height measure; CMS Weighing Equipment, Ltd., London, UK). Body weight was measured in duplicate to the nearest $0 \cdot 1 \mathrm{~kg}$ using digital scales. Waist circumference was measured in duplicate to the nearest $0 \cdot 1 \mathrm{~cm}$ midway between the top of the hip bone and the lower rib. The subjects were categorised according to the WHO BMI cut-offs for obesity ${ }^{(2)}$ as follows: normal weight (BMI 18.5-24.9 kg/m ${ }^{2}$ ), overweight (BMI $25 \cdot 0-29 \cdot 9 \mathrm{~kg} / \mathrm{m}^{2}$ ) and obese $\left(B M I \geq 30 \cdot 0 \mathrm{~kg} / \mathrm{m}^{2}\right)$. Abdominal obesity categories were defined as WAL, according to Lean et al. ${ }^{(21)}$, as follows: men - below action level $=0-93.99 \mathrm{~cm}$, WAL $1=94-101.9 \mathrm{~cm}$, WAL $2=>102.0 \mathrm{~cm}$; women below action level $=0-79.9 \mathrm{~cm}$, WAL $1=80.0-87.99 \mathrm{~cm}$, WAL $2=>88.0 \mathrm{~cm}$

\section{Exclusions}

At the end of the dietary recording period, the subjects completed questionnaires about illness during the recording period and whether this illness affected their eating. They were also asked questions on whether or not they were dieting to lose weight. Those who reported dieting ( $n$ 415) or that illness had affected their eating ( $n$ 210) during the recording period were excluded from the analysis. Subjects who were underweight (BMI $\left.<18.5 \mathrm{~kg} / \mathrm{m}^{2} ; n 58\right)$ and without complete dietary or anthropometry data were also excluded. The analyses were subsequently carried out on 1519 subjects.

\section{Statistical analyses}

All analyses were performed using SPSS version 11.5 (Statistical Package for Social Sciences, Chicago, IL, USA). Differences between men and women in baseline characteristics were assessed using $t$ tests; weight-status category, WAL and social class category were assessed by $\chi^{2}$ tests. All the data were assessed for normality and owing to the high level of skewness within the food groups, the groups were split into sex-specific quartiles for analysis. Mann-Whitney $U$ tests were used to assess the differences between men and women for the portion size $(\mathrm{g})$ of food groups consumed. UR between weight-status categories and quartiles of portion size was assessed using ANOVA. Multinomial logistic regression analyses were used to determine the associations between the portion sizes of food groups with weight-status category and WAL. This type of analysis was chosen as the proportion of overweight and obese subjects was much greater than that of the normal weight group; therefore, binomial logistic comparisons between normal weight and overweight/obese were not possible. Models were adjusted for age (model 1), social class, physical activity level (model 2) and model 2 plus UR (percentage of UR as a continuous variable; model 3). If model 1 was NS, no further analyses were done. Analyses were done separately for men and women. Results were considered significant at $P<0 \cdot 05$.

\section{Results \\ Subjects}

Subject characteristics, anthropometric measurements and social class categories of the 1519 subjects (689 men and 830 women) are presented in Table 1. There was no difference in age between the men and women $(P=0 \cdot 946)$. Women were significantly 
Table 1. Subject characteristics, anthropometric measures and social class groupings of men and women in the National Diet and Nutrition Survey (NDNS) of British Adults 2001

(Mean values and standard deviations or percentages)

\begin{tabular}{|c|c|c|c|c|c|}
\hline & \multicolumn{2}{|c|}{$\begin{array}{l}\text { Men }^{*} \\
n 689\end{array}$} & \multicolumn{2}{|c|}{$\begin{array}{c}\text { Women* } \\
n 830\end{array}$} & \multirow[b]{2}{*}{$P$} \\
\hline & Mean & SD & Mean & SD & \\
\hline Age (years) & $42 \cdot 4$ & 11.9 & $42 \cdot 3$ & 11.9 & 0.946 \\
\hline Weight (kg) & 84.4 & $13 \cdot 7$ & $69 \cdot 8$ & 14.9 & 0.001 \\
\hline Height $(m)$ & 1.8 & 0.7 & 1.6 & 0.7 & 0.001 \\
\hline BMI $\left(\mathrm{kg} / \mathrm{m}^{2}\right) \dagger \ddagger$ & $27 \cdot 2$ & 4.2 & $26 \cdot 7$ & $5 \cdot 6$ & 0.036 \\
\hline Normal (\%) & \multicolumn{2}{|c|}{31.3} & \multicolumn{2}{|c|}{$44 \cdot 7$} & 0.001 \\
\hline Overweight (\%) & \multicolumn{2}{|c|}{$44 \cdot 3$} & \multicolumn{2}{|c|}{34.2} & 0.387 \\
\hline Obese $(\%)$ & \multicolumn{2}{|c|}{24.4} & \multicolumn{2}{|c|}{$21 \cdot 1$} & 0.705 \\
\hline \multicolumn{6}{|l|}{ WAL† $\ddagger$} \\
\hline BAL (\%) & \multicolumn{2}{|c|}{$46 \cdot 8$} & \multicolumn{2}{|c|}{$44 \cdot 3$} & 0.110 \\
\hline WAL $1(\%)$ & \multicolumn{2}{|c|}{24.5} & \multicolumn{2}{|c|}{$28 \cdot 2$} & 0.001 \\
\hline WAL 2 (\%) & \multicolumn{2}{|c|}{$28 \cdot 7$} & \multicolumn{2}{|c|}{27.5} & 0.175 \\
\hline \multicolumn{6}{|l|}{ Social classt } \\
\hline Manual (\%) & \multicolumn{2}{|c|}{$46 \cdot 7$} & \multicolumn{2}{|c|}{$32 \cdot 2$} & 0.023 \\
\hline Non-manual (\%) & \multicolumn{2}{|c|}{$53 \cdot 3$} & \multicolumn{2}{|c|}{$67 \cdot 8$} & 0.001 \\
\hline
\end{tabular}

WAL, waist action level; BAL, below action level.

* Data between men and women are compared using independent $t$ tests.

†BMI, WAL and social class categories compared using $x^{2}$ tests.

$\ddagger \mathrm{BMl}$ categories are as follows: normal weight, $18.5-24.9 \mathrm{~kg} / \mathrm{m}^{2}$; overweight, $25.0-$ $29.9 \mathrm{~kg} / \mathrm{m}^{2}$; obese, $\geq 30.0 \mathrm{~kg} / \mathrm{m}^{2}$. WAL categories are as follows: BAL - men $<93.99$ $\mathrm{cm}$, women $<79.9 \mathrm{~cm}$; WAL $1-$ men $=94-101.9 \mathrm{~cm}$, WAL $1-$ women $=80.0$ $87.99 \mathrm{~cm}$; WAL 2 - men $>102.0 \mathrm{~cm}$, WAL 2 - women $>88.0 \mathrm{~cm}$.

shorter $(P<0.001)$, lighter $(P<0.001)$, had a lower BMI $(P=0.036)$ and were more likely to be of normal weight than men $(P<0.001)$. There were no differences in the proportion of men and women who were classified as either overweight $(P=0.387)$ or obese $(P=0 \cdot 705)$. Significantly more women than men were classified as having 'WAL 1' $(P<0 \cdot 001)$. No differences were observed in 'below action level' $(P=0.110)$ or 'WAL 2' $(P=0 \cdot 175)$ between men and women.

\section{Under-reporting}

UR was found to be 34 and $33 \%$ of estimated energy needs in men and women, respectively. UR was found to significantly increase with the weight-status categories (Fig. 1), and was the highest among the obese category in both men and women (37.1 and $38.2 \%$ of energy needs, respectively; $P<0.001$ ) compared with the normal and overweight categories.

\section{Portion sizes}

Men had significantly higher median intakes for almost all of the food groups compared with women (Table 2). The exceptions were low-fat milks, yoghurts, vegetables, fruits, juices and nuts, fish and beverages where there were no significant differences between the sexes. In the majority of food groups, the highest level of UR was observed in the lowest quartile of portion size.

\section{Eating occasions and energy intakes within and outside of the home}

Compared with the men, the women recorded significantly more (8.6 (SD 3.4) v. 7.6 (SD 3.6); $P<0.001$ ) in-home eating occasions but recorded significantly less (3.1 (SD 2.7) v. 4.9 (SD 3.2); $P<0.001$ ) out-of-home eating occasions.
Table 3 displays the mean daily in-home and out-of-home eating occasions and related EI for men and women across weight-status categories. In-home or out-of-home eating occasions or EI did not vary by weight-status category in men. However, overweight women recorded significantly more in-home eating occasions compared with obese women $(P=0.027)$, while normal weight women recorded significantly more out-of-home eating occasions compared with overweight women $(P=0 \cdot 011)$. EI consumed outside of the home was also significantly higher for normal weight women compared with overweight women $(P<0 \cdot 001)$.

\section{Portion sizes and BMI weight status}

Few positive associations were found between the portion sizes of food groups and BMI weight-status category (Table 4). In men, only three positive associations were found (whole milk, potatoes, and fresh meat). When the adjustment was made for UR, a further three food groups (breads and rolls, low-fat spreads and vegetables) became significantly positively associated with weight-status groupings. In women, only two positive associations were found (low-fat spreads and fish). When the adjustment was made for UR, a further four food groups (breads and rolls, low-fat milks, chips and processed potatoes and meat products) became significantly positively associated with weight-status groupings.

\section{Portion sizes and abdominal obesity categories}

Similar to BMI, few positive associations were found between the portion sizes of food groups with WAL (Table 5). In the men, no positive associations were found until the adjustment was made for UR, when two food groups (breads and rolls and low-fat spreads) became positively associated with WAL. In the women, four food groups (whole milk, chips and processed potatoes, meat products and beverages) were positively associated with WAL. After the adjustment was made for UR, a further three food groups (low-fat spreads, confectionery and soft drinks) were found to be positively associated with WAL.

\section{Discussion}

Recently, interest has been focused on the contribution that larger portion sizes may be making to the over-consumption of energy and thus the increasing prevalence of obesity. Studies carried out under semi-controlled laboratory conditions have shown that increasing food portion size can positively influence $\mathrm{EI}^{(6-8,12,13,22)}$ in the short term, but data on associations between the measures of adiposity with the amounts of foods consumed in free-living populations are extremely limited ${ }^{(14)}$

When these associations were examined in the NDNS (2001) adult survey, portions of some food groups (men: breads and rolls, low-fat spreads and vegetables; women: breads and rolls, low-fat milks, chips and processed potatoes and meat products) were not initially significantly positively associated with obesity status (BMI) but became so after the adjustment for the estimated degree of UR of EI. Similarly, five food groups (men: breads and rolls, low-fat spreads; women: low-fat spreads, confectionery and soft drinks) were 


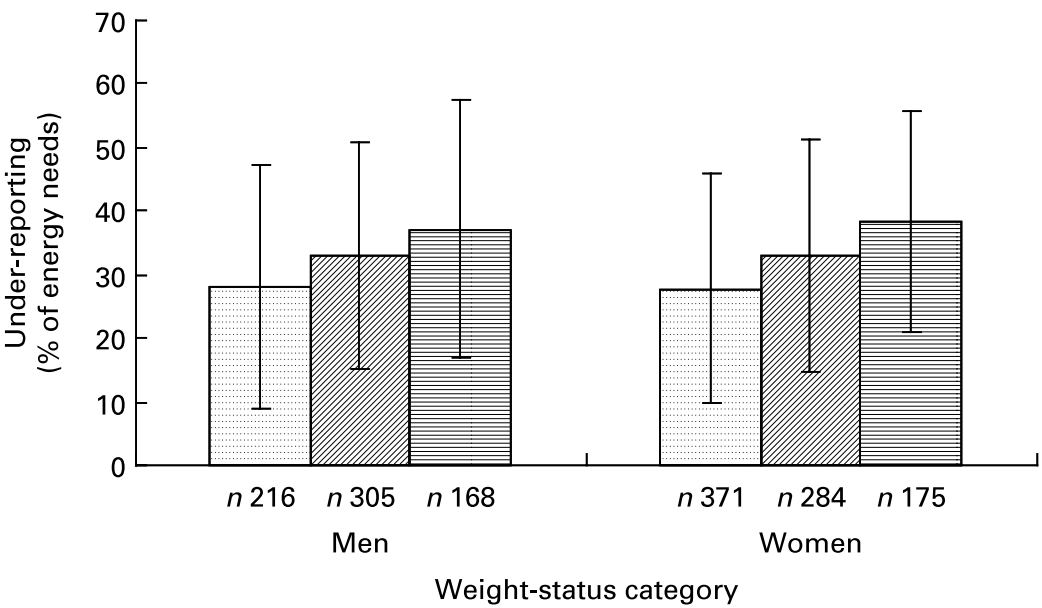

Fig. 1. Estimated under-reporting as a percentage of energy needs by weight-status category in the British National Diet and Nutrition Survey 2001. $\square$, normal; 口, overweight; $\boxminus$, obese. Data are presented as mean (SD), and are analysed using ANOVA. Men: normal-overweight, $P=0.014 ;$ normal-obese, $P<0.001$. Women: normal-overweight, $P<0.001$; overweight-obese, $P=0.010$; normal-obese, $P<0.001$.

only positively and significantly associated with abdominal obesity status (WAL) when the model was adjusted for UR of EI. These data demonstrate the importance of taking into account UR when assessing the association between diet and obesity status if false associations are to be avoided.
The present study has shown that in both men and women, irrespective of their weight-status category, the majority of eating occasions reported over the 7-d recording period occurred within the home. Although the reported frequency of in-home eating occasions was higher than out-of-home

Table 2. Median portion sizes of food groups for men and women in the National Diet and Nutrition Survey (NDNS) of British Adults 2001 (Medians and interquartile ranges (IQR))

\begin{tabular}{|c|c|c|c|c|c|c|c|c|c|}
\hline \multirow[b]{2}{*}{ Food group } & \multicolumn{4}{|c|}{ Men } & \multicolumn{4}{|c|}{ Women } & \multirow[b]{2}{*}{$P \dagger$} \\
\hline & $n^{\star}$ & Percentage* $^{*}$ & Median & IQR & $n^{\star}$ & Percentage* $^{*}$ & Median & IQR & \\
\hline Rice and pasta & 516 & 74.9 & $62 \cdot 8$ & $37,106 \cdot 2$ & 598 & 72 & $50 \cdot 6$ & $30 \cdot 1,87 \cdot 7$ & 0.001 \\
\hline Savouries & 359 & $52 \cdot 1$ & $26 \cdot 6$ & $11 \cdot 4,55 \cdot 6$ & 411 & $49 \cdot 5$ & $18 \cdot 5$ & $8 \cdot 7,35 \cdot 7$ & 0.001 \\
\hline All breads and rolls & 680 & $98 \cdot 7$ & $115 \cdot 1$ & $78 \cdot 8,163 \cdot 4$ & 813 & 98 & $78 \cdot 6$ & $53 \cdot 1,105 \cdot 4$ & 0.001 \\
\hline Breakfast cereals & 435 & $63 \cdot 1$ & $36 \cdot 8$ & $19,66 \cdot 8$ & 581 & 70 & $29 \cdot 3$ & $15 \cdot 3,50$ & 0.001 \\
\hline Biscuits, cakes and pastries & 569 & $82 \cdot 6$ & 33.4 & $16 \cdot 6,66 \cdot 3$ & 703 & $84 \cdot 7$ & $28 \cdot 8$ & 14,50 & 0.001 \\
\hline Whole milk & 254 & $36 \cdot 9$ & $99 \cdot 5$ & $29 \cdot 1,242 \cdot 8$ & 304 & $36 \cdot 6$ & $77 \cdot 0$ & $20 \cdot 1,178 \cdot 8$ & 0.010 \\
\hline Low-fat milks & 554 & 80.4 & $181 \cdot 4$ & $81.4,294.9$ & 682 & $82 \cdot 2$ & $165 \cdot 7$ & $80 \cdot 6,259$ & 0.145 \\
\hline Creams, ice creams and desserts & 349 & $50 \cdot 7$ & $32 \cdot 8$ & $17 \cdot 2,58 \cdot 9$ & 446 & 53.7 & $27 \cdot 0$ & $16 \cdot 1,48 \cdot 3$ & 0.002 \\
\hline Cheeses & 539 & $78 \cdot 2$ & $16 \cdot 6$ & $8 \cdot 8,29 \cdot 3$ & 622 & 74.9 & $14 \cdot 4$ & $8 \cdot 1,24 \cdot 3$ & 0.004 \\
\hline Yoghurts & 236 & $34 \cdot 3$ & $49 \cdot 8$ & $23 \cdot 5,77$ & 356 & $42 \cdot 9$ & $42 \cdot 8$ & $24 \cdot 7,79 \cdot 1$ & 0.744 \\
\hline Egg and egg dishes & 480 & $69 \cdot 7$ & 24.4 & $14 \cdot 3,43 \cdot 6$ & 552 & $66 \cdot 5$ & $20 \cdot 5$ & $11 \cdot 4,33$ & 0.001 \\
\hline Butter and spreads & 451 & 65.5 & $5 \cdot 8$ & $2 \cdot 6,12$ & 528 & $63 \cdot 6$ & $4 \cdot 2$ & $2,8 \cdot 9$ & 0.001 \\
\hline Low-fat spreads & 479 & 69.5 & $11 \cdot 1$ & $5 \cdot 8,18 \cdot 3$ & 538 & $64 \cdot 8$ & $7 \cdot 1$ & $3 \cdot 1,13$ & 0.001 \\
\hline Potatoes, boiled, mashed etc & 585 & 84.9 & $62 \cdot 6$ & $35,98 \cdot 2$ & 702 & $84 \cdot 6$ & $57 \cdot 1$ & $32 \cdot 3,91 \cdot 1$ & 0.030 \\
\hline Chips and processed potatoes & 584 & $84 \cdot 8$ & $53 \cdot 6$ & $29 \cdot 3,78 \cdot 9$ & 661 & $79 \cdot 6$ & $40 \cdot 7$ & $23 \cdot 6,64 \cdot 2$ & 0.001 \\
\hline Vegetable dishes & 553 & $80 \cdot 3$ & $26 \cdot 4$ & $13 \cdot 7,47 \cdot 9$ & 673 & $81 \cdot 1$ & $23 \cdot 2$ & $12 \cdot 8,41 \cdot 6$ & 0.012 \\
\hline Vegetables & 667 & $96 \cdot 8$ & $105 \cdot 6$ & $65.8,151.6$ & 818 & $98 \cdot 6$ & $98 \cdot 6$ & $59 \cdot 5,151 \cdot 1$ & 0.119 \\
\hline Fruits, juices and nuts & 505 & $73 \cdot 3$ & $61 \cdot 0$ & $26 \cdot 7,127 \cdot 4$ & 660 & 79.5 & $67 \cdot 9$ & $31 \cdot 8,135 \cdot 2$ & 0.065 \\
\hline Fish & 374 & $54 \cdot 3$ & $30 \cdot 0$ & $16 \cdot 3,52 \cdot 9$ & 493 & $59 \cdot 4$ & $27 \cdot 2$ & $13 \cdot 4,49$ & 0.076 \\
\hline Fish dishes and products & 245 & 35.6 & $25 \cdot 7$ & $19 \cdot 3,34 \cdot 2$ & 276 & $33 \cdot 3$ & $21 \cdot 6$ & $14 \cdot 7,27 \cdot 5$ & 0.001 \\
\hline Fresh meat & 662 & $96 \cdot 1$ & $133 \cdot 9$ & $90 \cdot 3,186 \cdot 4$ & 763 & 91.9 & $96 \cdot 2$ & $60 \cdot 9,143.7$ & 0.001 \\
\hline Meat dishes & 210 & 30.5 & $17 \cdot 35$ & $10 \cdot 5,30$ & 179 & $21 \cdot 6$ & $13 \cdot 1$ & $6 \cdot 3,22 \cdot 5$ & 0.002 \\
\hline Meat products & 573 & $83 \cdot 2$ & $48 \cdot 3$ & $25 \cdot 8,84 \cdot 1$ & 562 & $67 \cdot 7$ & $33 \cdot 6$ & $17 \cdot 3,54 \cdot 5$ & 0.001 \\
\hline Alcoholic beverages & 568 & $82 \cdot 4$ & $436 \cdot 3$ & $165 \cdot 1,851 \cdot 5$ & 621 & $74 \cdot 8$ & $122 \cdot 1$ & $42 \cdot 8,246 \cdot 4$ & 0.001 \\
\hline Sugars & 517 & $75 \cdot 0$ & $17 \cdot 6$ & $7 \cdot 1,35 \cdot 6$ & 587 & $70 \cdot 7$ & $9 \cdot 4$ & $3 \cdot 6,20 \cdot 5$ & 0.001 \\
\hline Confectionery & 409 & $59 \cdot 4$ & $14 \cdot 2$ & $7 \cdot 6,35 \cdot 6$ & 536 & $64 \cdot 6$ & $12 \cdot 3$ & $6 \cdot 1,22 \cdot 8$ & 0.003 \\
\hline Savoury snacks & 369 & 53.6 & 11.6 & $5 \cdot 5,19 \cdot 6$ & 465 & 56 & $8 \cdot 3$ & $4 \cdot 6,14 \cdot 3$ & 0.001 \\
\hline Soups and sauces & 659 & $95 \cdot 6$ & $40 \cdot 3$ & $18 \cdot 4,74 \cdot 7$ & 786 & $94 \cdot 7$ & $34 \cdot 0$ & $14 \cdot 8,69$ & 0.018 \\
\hline Beverages & 683 & $99 \cdot 1$ & 944.6 & $641 \cdot 2,1289.8$ & 825 & 99.4 & $965 \cdot 7$ & $614.9,1348.5$ & 0.868 \\
\hline Soft drinks & 413 & 59.9 & $124 \cdot 4$ & $51 \cdot 5,317 \cdot 8$ & 454 & $54 \cdot 7$ & $99 \cdot 0$ & $47 \cdot 1,218 \cdot 7$ & 0.008 \\
\hline
\end{tabular}

${ }^{*}$ Number and percentage of consumers of food group.

$\dagger$ Data between men and women are compared using Mann-Whitney $U$ tests. 
Table 3. Daily eating occasions and energy intake (EI) in-home and out-of-home over $7 \mathrm{~d}$ by weight-status category* (Mean values and standard deviations)

\begin{tabular}{|c|c|c|c|c|c|c|c|c|c|c|c|c|}
\hline & \multicolumn{4}{|c|}{ Normal weight† } & \multicolumn{4}{|c|}{ Overweight† } & \multicolumn{4}{|c|}{ Obese† } \\
\hline & \multicolumn{2}{|c|}{$\begin{array}{l}\text { Eating } \\
\text { occasions }\end{array}$} & \multicolumn{2}{|c|}{ Energy (MJ) } & \multicolumn{2}{|c|}{ Eating occasions } & \multicolumn{2}{|c|}{ Energy (MJ) } & \multicolumn{2}{|c|}{$\begin{array}{l}\text { Eating } \\
\text { occasions }\end{array}$} & \multicolumn{2}{|c|}{ Energy (MJ) } \\
\hline & Mean & SD & Mean & SD & Mean & SD & Mean & SD & Mean & SD & Mean & SD \\
\hline \multicolumn{13}{|l|}{ Men‡ } \\
\hline In-home§ & $7 \cdot 25$ & 3.47 & $6 \cdot 13$ & 2.45 & $7 \cdot 72$ & $3 \cdot 61$ & $6 \cdot 34$ & 2.49 & $7 \cdot 66$ & 3.56 & $6 \cdot 56$ & 2.69 \\
\hline Out-of-home & $5 \cdot 22$ & 3.25 & 3.76 & 2.43 & 4.75 & 3.29 & 3.40 & $2 \cdot 38$ & 4.65 & $3 \cdot 10$ & 3.37 & $2 \cdot 27$ \\
\hline \multicolumn{13}{|l|}{ Women } \\
\hline In-home§ & 8.58 & 3.52 & $5 \cdot 07$ & 1.84 & $9 \cdot 01$ & 3.43 & $5 \cdot 20$ & 1.74 & $8 \cdot 15 \|$ & $3 \cdot 12$ & $5 \cdot 13$ & 1.88 \\
\hline Out-of-home & 3.45 & $2 \cdot 84$ & 2.05 & 1.64 & $2 \cdot 849$ & 2.54 & $1 \cdot 60^{\star *}$ & 1.33 & $2 \cdot 88$ & $2 \cdot 41$ & 1.77 & 1.33 \\
\hline
\end{tabular}

*Data are presented as mean daily eating occasions (frequency) and EI (MJ) per eating occasion by weight-status category. Data across weight-status categories are assessed using ANOVA.

** Significantly different from normal weight out-of-home El.

† Normal weight (BMI 18.5-24.9 kg/m²), overweight (BMI $\left.25 \cdot 0-29 \cdot 9 \mathrm{~kg} / \mathrm{m}^{2}\right)$, obese $\left(B M I \geq 30.0 \mathrm{~kg} / \mathrm{m}^{2}\right)$.

$\ddagger$ Significantly different from women for in-home and out-of-home eating occasions.

$\S$ Significantly different from out-of-home eating occasions.

II Significantly different from overweight in-home eating occasions.

I Significantly different from normal weight out-of-home eating occasions.

Table 4. Associations between portion sizes (g) of food groups consumed with BMI status category in men and women in the National Diet and Nutrition Survey (NDNS) of British adults 2001*

\begin{tabular}{|c|c|c|c|c|}
\hline \multirow[b]{3}{*}{ Food group } & \multicolumn{4}{|c|}{ BMI† } \\
\hline & \multicolumn{2}{|c|}{ Men } & \multicolumn{2}{|c|}{ Women } \\
\hline & Model 2ł & Model 3ł & Model $2 \ddagger$ & Model 3ł \\
\hline Rice and pasta & 0.267 & 0.340 & 0.769 & 0.543 \\
\hline Savouries & 0.797 & 0.854 & 0.134 & 0.097 \\
\hline All breads and rolls & 0.393 & 0.010 & 0.780 & 0.042 \\
\hline Breakfast cereals & 0.491 & 0.072 & 0.623 & 0.585 \\
\hline Biscuits, cakes and pastries & 0.591 & 0.595 & 0.345 & 0.137 \\
\hline Whole milk & 0.019 & 0.049 & NS & NS \\
\hline Low-fat milks & 0.849 & 0.302 & 0.122 & 0.032 \\
\hline Creams, ice creams and desserts & 0.765 & 0.481 & 0.057 & 0.123 \\
\hline Cheeses & 0.332 & 0.193 & 0.907 & 0.715 \\
\hline Yoghurts & 0.756 & 0.806 & 0.162 & 0.233 \\
\hline Egg and egg dishes & 0.940 & 0.726 & 0.868 & 0.775 \\
\hline Butter and spreads & 0.774 & 0.928 & 0.316 & 0.494 \\
\hline Low-fat spreads & 0.092 & 0.006 & 0.001 & 0.001 \\
\hline Potatoes, boiled, mashed etc & 0.004 & 0.003 & 0.780 & 0.758 \\
\hline Chips and processed potatoes & 0.219 & 0.329 & 0.189 & 0.054 \\
\hline Vegetable dishes & 0.304 & 0.206 & 0.958 & 0.990 \\
\hline Vegetables & 0.124 & 0.021 & 0.526 & 0.296 \\
\hline Fruits, juices and nuts & 0.144 & 0.419 & 0.073 & 0.178 \\
\hline Fish & NS & NS & 0.020 & 0.010 \\
\hline Fish dishes and products & NS & NS & 0.212 & 0.162 \\
\hline Fresh meat & 0.049 & 0.006 & 0.691 & 0.473 \\
\hline Meat dishes & 0.526 & 0.585 & 0.861 & 0.855 \\
\hline Meat products & 0.343 & 0.308 & 0.092 & 0.009 \\
\hline Alcoholic beverages & 0.940 & 0.965 & 0.202 & 0.071 \\
\hline Sugars & 0.718 & 0.909 & 0.545 & 0.948 \\
\hline Confectionery & NS & NS & 0.893 & 0.444 \\
\hline Savoury snacks & 0.361 & 0.358 & 0.717 & 0.789 \\
\hline Soups, sauces & 0.895 & 0.897 & 0.882 & 0.897 \\
\hline Beverages & 0.515 & 0.729 & 0.057 & 0.452 \\
\hline Soft drinks & 0.089 & $0 \cdot 100$ & 0.791 & 0.581 \\
\hline
\end{tabular}

* Data are analysed using multinomial logistic regression analysis. Numbers represent $P$ values. $P$ values are trends across the BMI categories.

$\dagger$ †MI categories are as follows: normal weight, $18.5-24.9 \mathrm{~kg} / \mathrm{m}^{2}$; overweight, BMI $25 \cdot 0-29.9 \mathrm{~kg} / \mathrm{m}^{2}$; obese, $\mathrm{BMI} \geq 30.0 \mathrm{~kg} / \mathrm{m}^{2}$.

¥ Model 1 adjusted for age, model 2 adjusted for age, physical activity level and social class, and model $3=$ model $2+$ adjusted for percentage of UR. All significant associations are positive. $P>0.05$ in model 1 is NS. 
Table 5. Associations between portion sizes (g) of food groups consumed and waist action level (WAL) category in men and women in the National Diet and Nutrition Survey (NDNS) of British adults 2001*

\begin{tabular}{|c|c|c|c|c|}
\hline \multirow[b]{3}{*}{ Food group } & \multicolumn{4}{|c|}{ WAL† } \\
\hline & \multicolumn{2}{|c|}{ Men } & \multicolumn{2}{|c|}{ Women } \\
\hline & Model $2 \ddagger$ & Model 3‡ & Model $2 \ddagger$ & Model 3‡ \\
\hline Rice and pasta & 0.487 & 0.535 & 0.948 & 0.876 \\
\hline Savouries & 0.981 & 0.988 & 0.113 & 0.093 \\
\hline All breads and rolls & 0.473 & 0.017 & 0.161 & 0.064 \\
\hline Breakfast cereals & 0.827 & 0.772 & 0.856 & 0.865 \\
\hline Biscuits, cakes and pastries & 0.866 & 0.641 & 0.673 & 0.352 \\
\hline Whole milk & 0.486 & 0.670 & 0.025 & 0.015 \\
\hline Low-fat milks & 0.853 & 0.544 & 0.597 & 0.204 \\
\hline Creams, ice creams and desserts & 0.760 & 0.620 & 0.222 & 0.315 \\
\hline Cheeses & $0 \cdot 616$ & 0.269 & 0.632 & 0.531 \\
\hline Yoghurts & 0.362 & 0.454 & 0.099 & 0.132 \\
\hline Egg and egg dishes & 0.598 & 0.551 & 0.759 & 0.753 \\
\hline Butter and spreads & 0.599 & 0.601 & 0.625 & 0.506 \\
\hline Low-fat spreads & 0.092 & 0.004 & 0.073 & 0.042 \\
\hline Potatoes, boiled, mashed etc & 0.936 & 0.857 & 0.427 & 0.355 \\
\hline Chips and processed potatoes & 0.456 & 0.412 & 0.019 & 0.002 \\
\hline Vegetable dishes & 0.586 & 0.453 & 0.090 & 0.094 \\
\hline Vegetables & 0.410 & 0.108 & 0.474 & 0.552 \\
\hline Fruits, juices and nuts & 0.236 & 0.664 & 0.074 & 0.058 \\
\hline Fish & 0.624 & 0.601 & 0.289 & 0.220 \\
\hline Fish dishes and products & 0.406 & 0.343 & 0.704 & 0.755 \\
\hline Fresh meat & 0.709 & 0.435 & 0.959 & 0.884 \\
\hline Meat dishes & 0.518 & 0.437 & 0.753 & 0.589 \\
\hline Meat products & 0.412 & 0.322 & 0.001 & 0.001 \\
\hline Alcoholic beverages & 0.250 & 0.169 & 0.255 & 0.164 \\
\hline Sugars & 0.059 & 0.062 & 0.881 & 0.951 \\
\hline Confectionery & 0.646 & 0.407 & 0.238 & 0.049 \\
\hline Savoury snacks & 0.676 & 0.673 & 0.966 & 0.952 \\
\hline Soups, sauces & 0.749 & 0.746 & 0.413 & 0.518 \\
\hline Beverages & 0.446 & 0.661 & 0.002 & 0.013 \\
\hline Soft drinks & 0.093 & 0.061 & 0.177 & 0.044 \\
\hline
\end{tabular}

BAL, below action level.

* Data are analysed using multinomial logistic regression analysis. Numbers represent $P$ values. $P$ values are trends across the WAL categories.

†WAL categories are as follows: BAL (men $<93.99 \mathrm{~cm}$, women $<79.9 \mathrm{~cm}$ ); WAL 1 men $=94-101.9 \mathrm{~cm}, \mathrm{WAL} 1 \mathrm{women} 80.0-87.99 \mathrm{~cm}$; WAL $2=\mathrm{men}>102.0 \mathrm{~cm}, \mathrm{WAL} 2$ women $>88.0 \mathrm{~cm}$.

$\ddagger$ Model 1 adjusted for age, model 2 adjusted for age, physical activity level and social class, and model $3=$ model $2+$ adjusted for percentage of UR. All significant associations are positive.

eating occasions, it is not clear whether this is a true reflection of their usual eating patterns.

Only one previous observational study has attempted to quantify the risk of excess body fatness with food portion sizes of foods consumed by free-living adults ${ }^{(14)}$. Adiposity was positively associated with the consumption of large portions of specific foods (savoury snacks, butter, full-fat spreads, meat products and dishes and chips and processed potatoes) in Irish adults. By contrast, a different range of food groups (breads and rolls, whole milk, low-fat spreads, chips and processed potatoes, fresh meat, meat products) were positively associated with a higher BMI or waist circumference in British adults. Both studies, however, found that increased portion sizes of specific food groups were associated with increased BMI and WAL. The food groups examined in both studies were very similar and some of these food groups (meat products, chips and processed potatoes) were found to be strongly associated with measures of adiposity in both studies.

Although both surveys were conducted in a representative sample of free-living adults using 7-d dietary record methodology, in the present study food intake was quantified by direct weighing, while the earlier study relied on estimating food weights using standardised portion sizes. To what extent the difference in the methods of assessing portion weights of foods eaten explains these findings are unclear. On the other hand, it may be that there are real dietary differences between the two populations. Both studies adjusted for the potential impact of energy misreporting. McCarthy et al. ${ }^{(14)}$ used the ratio of EI to estimated BMR (EI:BMR), whereas a more specific calculation using physical activity data and a continuous variable based on collated doubly labelled water energy expenditure data ${ }^{(19)}$ was used in the present analyses. As previously reported, there is a high level of UR in the NDNS ${ }^{(23)}$. In the present analyses, UR of energy needs was estimated at 34 and $33 \%$ in the men and women, respectively, and furthermore there was a higher level of UR among overweight and obese adults compared with those of a normal weight adult, which has been previously observed $^{(24,25)}$. The adjustment for UR is a vital consideration when assessing possible relationships between dietary intakes and variables of interest, since this may lead to the attenuation of associations when levels of misreporting are high ${ }^{(26)}$. The results of the present study emphasised the importance of adjusting for UR when examining the relationships between the portion sizes of food groups consumed with measures of adiposity. The high levels of UR of EI observed in the NDNS and the subsequent adjustment for UR in the statistical models did have an impact on 
the associations between the portion sizes of food groups consumed with BMI and WAL in both the men and women. If the UR of energy needs had not been adjusted for, the observed associations may have been missed or it could have been concluded that there are no associations between the portion sizes of food groups consumed with obesity status.

A number of issues of UR are pertinent to the present discussion. First, whether misreporting is due, at least partially, by misrepresentation of usual portion sizes consumed. We found that adjustment for UR significantly affected the interpretation of associations between food portion sizes and measures of body fatness (BMI and WAL). Since dietary intake in free-living individuals in studies is self-reported, there is the opportunity for both measurement error and misreporting of food portion size, which in turn affects the estimate of overall EI.

Second, it is possible that any associations were masked by study participants who used the recording period as an opportunity to change their eating behaviour or to diet. Since undereating while recording food intake has been observed in lean and obese adults ${ }^{(27)}$, we were careful to exclude from the analysis, those subjects who reported dieting during the recording period. Nevertheless, it is likely that the dataset did include subjects who were limiting their intake during the recording period but who consciously or subconsciously failed to declare this. Body weight was only measured once during the recording period; therefore, it was not possible to examine the changes in body weight as a means of detecting under-consumption of food intake.

The third issue is whether UR is associated with the achievement of a self-presentation goal on the part of the study participant. It has been suggested that instead of modifying the diet, specific foods are under-reported or omitted in order to appear in a socially favourable light ${ }^{(28)}$. Lafay et al. ${ }^{(29)}$ suggested that the UR of food intake seems to concern food items that are generally considered 'bad for health'. This may have been the case in the NDNS, where there may have been a possible tendency to under-report or even exclude the foods that are considered to be 'unhealthy' or associated with obesity, such as savoury snacks, creams, ice creams and desserts, biscuits, cakes and soft drinks. However, it was not possible to systematically assess whether there was UR of specific foods in the NDNS as only estimates of UR of EI were feasible. There is also the possibility that foods that were perceived as healthy may have been overreported; however, there are no available data to support this contention. Consequently, the causal associations between food portion size and obesity remain unclear, owing not only to the cross-sectional nature of food consumption surveys but also to the misreporting of food intake of unknown magnitude and direction.

In the present study, it is highly likely that UR may have masked any true associations between the food portion sizes consumed with measures of obesity. Alternatively, portion sizes of specific foods or food groups in isolation may not be major contributing factors to obesity risk, rather it may be the consumption of a larger range of foods and food groups. Gaining a better understanding of the influence of food portion size on EI and obesity may be a crucial step in identifying a modifiable dietary factor that may be influencing the current epidemic of overweight and obesity.

\section{Acknowledgements}

This research was commissioned by the Food Standards Agency (research project N09021). Ethical approval for the NDNS survey was granted by a Multi-centre Research Ethics Committee (MREC). Approval was also sought from National Health Service Local Research Ethics Committees (LREC) in the areas where the fieldwork took place. There are no conflicts of interest. The contributions of the authors were as follows: M. B. E. L. was the principal investigator and is the guarantor. M. T. K. and K. L. R. performed data analysis and wrote the manuscript. M. B. E. L., J. M. W., P. J. R., R. W. W. and M. P. H. F. contributed to data analysis and to the writing of the manuscript.

The present paper forms part of the dissemination of the Food Standards Agency-commissioned research project N09021.

\section{References}

1. House of Commons Health Committee (2001) Tackling Obesity in England. London: The Stationery Office.

2. World Health Organisation (1998) Obesity: Preventing and Managing the Global Epidemic. International Obesity Task Force Report. Geneva: WHO.

3. Nielsen SJ \& Popkin BM (2003) Patterns and trends in food portion sizes, 1977-1998. J Am Med Assoc 289, 450-453.

4. Smiciklas-Wright H, Mitchell DC, Mickle SJ, Goldman JD \& Cook A (2003) Foods commonly eaten in the United States, 1989-1991 and 1994-1996: are portion sizes changing? J Am Diet Assoc 103, 41-47.

5. Frobisher C \& Maxwell SM (2003) The estimation of food portion sizes: a comparison between using descriptions of portion sizes and a photographic food atlas by children and adults. J Hum Nutr Diet 16, 181-188.

6. Rolls BJ, Morris EL \& Roe LS (2002) Portion size of food affects energy intake in normal-weight and overweight men and women. Am J Clin Nutr 76, 1207-1213.

7. Rolls BJ, Roe LS, Kral TV, Meengs JS \& Wall DE (2004) Increasing the portion size of a packaged snack increases energy intake in men and women. Appetite 42, 63-69.

8. Rolls BJ, Roe LS, Meengs JS \& Wall DE (2004) Increasing the portion size of a sandwich increases energy intake. J Am Diet Assoc 104, 367-372.

9. Wansink B \& Cheney MM (2005) Super Bowls: serving bowl size and food consumption. J Am Med Assoc 293, 1727-1728.

10. Wansink B \& Kim J (2005) Bad popcorn in big buckets: portion size can influence intake as much as taste. J Nutr Educ Behav 37, 242-245.

11. Wansink B, Painter JE \& North J (2005) Bottomless bowls: why visual cues of portion size may influence intake. Obes Res 13, $93-100$.

12. Rolls BJ, Roe LS \& Meengs JS (2006) Larger portion sizes lead to sustained increases in energy intake over 2 days. $J$ Am Diet Assoc 106, 543-549.

13. Rolls BJ, Roe LS \& Meengs JS (2007) The effect of large portion sizes on energy intake is sustained for 11 days. Obesity (Silver Spring) 15, 1535-1543.

14. McCarthy SN, Robson PJ, Livingstone MB, Kiely M, Flynn A, Cran GW \& Gibney MJ (2006) Associations between daily food intake and excess adiposity in Irish adults: towards the development of food-based dietary guidelines for reducing the prevalence of overweight and obesity. Int J Obes (Lond) 30, 993-1002.

15. Henderson L, Gregory J \& Swan G (2002) The National Diet and Nutrition Survey: adults aged 19 to 64 years, Technical 
Report. Social Survey Division of the Office for National Statistics 16, 2002. London: TSO.

16. Bell AC \& Swinburn BA (2004) What are the key food groups to target for preventing obesity and improving nutrition in schools? Eur J Clin Nutr 52, 258-263.

17. Ludwig DS, Peterson KE \& Gortmaker SL (2001) Relation between consumption of sugar-sweetened drinks and childhood obesity: a prospective, observational analysis. Lancet 357, 505-508.

18. Rennie KL, Coward A \& Jebb SA (2007) Estimating underreporting of energy intake in dietary surveys using an individualised method. Br J Nutr 97, 1169-1176.

19. Institute of Medicine of the National Academies (2002) Dietary Reference Intakes for Energy, Carbohydrate, Fibre, Fat, Fatty Acids, Cholesterol, Protein and Amino Acids. Washington, DC: National Academies Press.

20. Ruston D, Hoare J, Henderson L, Gregory J, Bates C, Prentice A, Birch M, Swan G \& Farron M (2000) The National Diet and Nutrition Survey: Adults Aged 19-64 Years; Nutritional Status (Anthropometry and Blood Analytes) Blood Pressure and Physical Activity, vol. 4. London: TSO.

21. Lean MEJ, Han TS \& Morrison CE (1995) Waist circumference as a measure for indicating need for weight management. BMJ 311, 158-161.
22. Rolls BJ, Roe LS \& Meengs JS (2004) Salad and satiety: energy density and portion size of a first-course salad affect energy intake at lunch. J Am Diet Assoc 104, 1570-1576.

23. Rennie KL, Jebb SA, Wright A \& Coward WA (2005) Secular trends in under-reporting in young people. Br J Nutr 93, 241-247.

24. Heitmann BL \& Lissner L (1995) Dietary under-reporting by obese individuals - is it specific or non-specific? BMJ 311, 986-989.

25. Prentice AM, Black AE, Coward WA, Davies HL, Goldberg GR, Murgatroyd PR, Ashford J, Sawyer M \& Whitehead RG (1986) High levels of energy expenditure in obese women. BMJ (Clin Res Ed) 292, 983-987.

26. Livingstone MB \& Black AE (2003) Markers of the validity of reported energy intake. J Nutr 133, Suppl. 3, 895S-920S.

27. Westerterp KR \& Goris AHC (2002) Validity of the assessment of dietary intake: problems of misreporting. Curr Opin Clin Nutr Metab Care 5, 489-493.

28. Hebert JR, Clemow L, Pbert L, Ockene IS \& Ockene JK (1995) Social desirability bias in dietary self-report may compromise the validity of dietary intake measures. Int J Epidemiol 24, 389-398.

29. Lafay L, Mennen L, Basdevant A, Charles MA, Borys JM, Eschwege E \& Romon M (2000) Does energy intake underreporting involve all kinds of food or only specific food items? Results from the Fleurbaix Laventie Ville Sante (FLVS) study. Int J Obes Relat Metab Disord 24, 1500-1506. 